\title{
Caution when treating tuberculosis in malnourished children
}

\author{
Kazeem Adeola Oshikoya, ${ }^{1}$ Idowu Odunayo Senbanjo ${ }^{2}$
}

Tuberculosis (TB) is one of the 10 leading causes of death worldwide. ${ }^{1}$ The WHO in 2016 estimated that 1 million children $<15$ years old suffer from TB and 250000 died of this condition (including children with HIV-associated TB). ${ }^{2}$

Malnutrition and TB are problems of enormous magnitude in most low-income and middle-income countries, which carry the burden of $95 \%$ of cases and deaths from $\mathrm{TB},{ }^{3}$ and both problems are compounded in a high proportion of affected children. Nutrition is significantly poorer among patients with active TB compared with healthy controls. ${ }^{4}$ Both macronutrient and micronutrient deficiencies increase the risk of developing TB and of having poorer outcomes from TB. ${ }^{4}$ Malnourished patients with TB have delayed recovery and higher mortality rates than well-nourished patients; however, the nutritional status of patients with both conditions invariably improves when they receive effective TB chemotherapy. ${ }^{3}$ The high prevalence of HIV infection in low-income and middle-income countries further aggravates the problem of malnutrition and TB.

The WHO and various countries with high burden of TB have published guidelines for nutrition in TB and HIV infection. These guidelines have limited information on the gaps in knowledge regarding the disposition of anti-TB drugs in individuals suffering from $\mathrm{TB}$ and malnutrition, or TB, HIV infection and malnutrition. ${ }^{6}$ This is, however, an area that ought to be prioritised for research.

The clinical response to medications differs between patients, and TB chemotherapy is no exception. A known source of individual variability is the nutritional status. ${ }^{7}$ The quality and quantity of hepatic metabolising enzymes are

\footnotetext{
${ }^{1}$ Pharmacology, Therapeutic and Toxicology Department, Lagos State University College of Medicine, Lagos, Nigeria

2Paediatric and Child Health Department, Paediatric Gastroenterology, Hepatology and Nutrition Unit, Lagos State University College of Medicine, Lagos, Nigeria
}

Correspondence to Dr Kazeem Adeola Oshikoya, Pharmacology, Therapeutic and Toxicology Department, Lagos State University College of Medicine, Lagos 234, Nigeria; med_modhospital@yahoo.com significantly reduced in malnourished children, ${ }^{78}$ yet doses of anti-TB drugs, which are primarily metabolised in the liver, are rarely modified during acute malnutrition. In malnutrition there is reduced renal clearance of drugs that are primarily excreted through the kidney, and doses of such drugs are not routinely modified in clinical practice or treatment guidelines. ${ }^{8}$ Thus, administering to malnourished children the doses of drugs, especially those with narrow therapeutic index, recommended for well-nourished children can potentially result in adverse drug toxicities, morbidity and mortality. However, the impact of impaired anti-TB drug disposition on the morbidity and mortality of severely malnourished children has not been adequately investigated.

Important pharmacokinetic parameters used to describe drug metabolism include the maximum plasma concentration after a single dose $\left(\mathrm{C}_{\max }\right)$, time taken to attain the maximal plasma concentration $\left(\mathrm{T}_{\max }\right)$, area under the curve (AUC) of a plot of plasma drug concentration versus time, clearance (CL) and half-life $\left(t_{1 / 2}\right)$. Results from a recent systematic review showed that the disposition of two anti-TB drugs (isoniazid (INH) and ethambutol) had been evaluated in malnourished children. ${ }^{8}$ Among children with kwashiorkor, the total clearance (CL) of INH significantly decreased, while the half-life $\left(t_{1 / 2}\right)$ significantly increased. However, there was no significant difference in the half-life of INH in underweight compared with well-nourished control children. ${ }^{8}$ Roy et $a l^{9}$ reported no significant difference in the serum concentrations of $\mathrm{INH}$ in moderately malnourished and well-nourished children. Among children treated for TB with thrice-weekly pyrazinamide (PZA) or ethambutol, the maximum concentration $\left(\mathrm{C}_{\max }\right)$ for PZA was significantly reduced in severely malnourished compared with their well-nourished counterparts. However, the $\mathrm{C}_{\max }$ for ethambutol showed no significant difference when compared for both groups of children. ${ }^{10}$ This suggests that various degrees of malnutrition impact on drug disposition differently. Ethambutol is eliminated primarily in the kidney; its CL and $t_{1 / 2}$ did not differ for underweight and marasmic children compared with well-nourished control group. ${ }^{8}$ Mukherjee et al ${ }^{11}$ evaluated several pharmacokinetic parameters $\left(\mathrm{C}_{\max }, \mathrm{T}_{\max }\right.$ and area under the curve from 0 to 4 hours $\left(\mathrm{AUC}_{0-4 \mathrm{~h}}\right)$ ) of INH, rifampicin (RMP), ethambutol and PZA in severely malnourished and well-nourished children after administering the WHO standard and revised doses for children. There was no significant difference in each pharmacokinetic parameter when the two groups of children were compared. In spite of these data, INH and other anti-TB drugs are prescribed for children based on their weight band for age according to the revised WHO guidelines. The WHO recommends the use of standard-dose combination anti-TB therapy that includes rifampicin (R), isoniazid $(\mathrm{H})$, pyrazinamide $(\mathrm{Z})$ or ethambutol $(\mathrm{E})$ in all children; however, there is a lack of adequate information on the disposition of these drugs in severely malnourished children. In drug-susceptible pulmonary $\mathrm{TB}$, the 6-month RMP-based regimen 2HRZE/4HR remains the recommended first-line regimen, hence the need for more studies on the disposition of these drugs in malnourished children to guide their appropriate dosing.

In this issue of Archives of Disease in Childhood, Singh et al report the impact of age and nutritional status on the population pharmacokinetic study of INH and PZA in 37 children. The study excluded children with other clinical conditions that are associated with malnutrition, such as HIV infection, and chronic hepatic or renal diseases. The study was limited to children aged 1-15 years with pulmonary or extrapulmonary TB in the initiation phase of the four combined first-line anti-TB (2HRZE) and for at least 15 days of anti-TB treatment. The nutritional status of children under 5 years of age was assessed according to the WHO standards for weight-for-height (<-2: wasting), weight-for-age $(<-2$ : underweight $)$ or height-for-age $(<-2$ : stunting) $\mathrm{z}$-scores. The authors also classified the nutritional status of older children based on body mass index (BMI) as severe malnutrition $(\mathrm{BMI}<-2)$ and well-nourished $(\mathrm{BMI} \geq-2)$. However, the normallynourished control groups that were used to compare each malnourished group differ and can potentially influence the findings.

The major outcomes measured were the $\mathrm{C}_{\max }$ and the area under the curve from 0 to 8 hours $\left(\mathrm{AUC}_{0-8 \mathrm{~h}}\right)$ for both INH and PZA for different categories of malnutrition. Similar to some previous studies, other important pharmacokinetic parameters 
such as the CL and $t_{1 / 2}$ of both drugs were not determined. The $\mathrm{C}_{\max }$ represents the rate of absorption and the $\mathrm{AUC}_{0-8 \mathrm{~h}}$ represents the extent of total drug absorption over the 8-hour period. Both parameters therefore reflect the extent of drug availability and are sufficiently sensitive in determining the therapeutic level of INH and PZA in the blood, but are insufficiently sensitive in determining the likelihood of toxicity, since drug toxic level is much more dependent on its CL and $t_{1 / 2}$. For INH, the $\mathrm{C}_{\max }$ and AUC for underweight, stunted, wasted and severely malnourished children did not significantly differ from those of their respective well-nourished counterparts. However, the results were contrasting for PZA when severely malnourished older children (low BMI) were compared with well-nourished children of similar age (with normal $\mathrm{BMI}$ ). Both $\mathrm{C}_{\max }$ and $\mathrm{AUC}_{0-8 \mathrm{~h}}$ were significantly reduced in malnourished children compared with their normally nourished counterparts. The $\mathrm{C}_{\max }$ for PZA in underweight, stunted and wasted children did not significantly differ from those of their respective well-nourished controls. But the $\mathrm{AUC}_{0-8 \mathrm{~h}}$ for stunted and wasted children was significantly lower compared with their well-nourished counterparts. Regardless of the study limitations, Singh et al did not make a definitive conclusion on the clinical outcome of TB in malnourished children with low availability of PZA.
The results from this study reiterate the importance of recognising the differences in the spectrum of malnutrition, rather than seeing it as a single disease entity. Since different degrees of malnutrition affect drug disposition differently, a rational approach is advocated to appropriately evaluate the influences of malnutrition on drug disposition. The current data are limited to two of the first-line anti-TB drugs that have been previously studied and did not include the pharmacokinetic parameters that are most closely linked to drug toxicity. Other studies evaluating the pharmacokinetic parameters of first-line anti-TB drugs in malnourished and well-nourished children rarely assessed the hepatic or renal clearance and half-life of the drugs (table 1). In a few cases where these parameters were assessed, the results were inconsistent and did not provide adequate data regarding their potential toxicity. To confound the situation malnourished children may have extrapulmonary TB or experience a multidrug-resistant TB that requires prolonged treatment and the use of second line anti-TB drugs, about which even less is known. The risk of potential toxicity of the second-line anti-TB is much higher in malnourished children compared with those who are well-nourished. This is attributed to the reduced hepatic or renal clearance of the drugs in malnourished children. $^{7} \quad$ Furthermore, malnutrition often coexists with bacterial infections, malaria, TB and/or HIV infection and may require treatment with complex and potentially interacting drugs and newer antibiotics. In general there is paucity of population pharmacokinetic studies of many of the drugs frequently administered to malnourished children. To further advance this field, collaboration between experts in child nutrition and those in drug disposition is required.

In vivo studies evaluating the potential toxicity of INH or RMP in children are scarce. However, there are case reports of potential clinical toxicity of these drugs. A 5-year-old boy with latent TB infection developed fulminant hepatic failure 5 months after commencing INH (11 mg/ kg daily). ${ }^{12}$ This was characterised by severe jaundice, markedly elevated aspartate transaminase and alanine transaminase, prolonged international normalised ratio, and signs of hepatic encephalopathy. Following INH discontinuation, all the problems resolved completely after 6 months. Similar idiosyncratic drug-induced reaction has been reported in two different studies in the USA among children with latent TB infection treated with INH only. ${ }^{1314}$ In one of the studies, a child with fulminant hepatitis had a liver transplant. ${ }^{14}$ $\mathrm{INH}$ is used in combination with rifampicin as chemoprophylaxis, and it may be difficult to know which drug is responsible for an adverse toxicity. Hepatotoxicity and

Table 1 Effect of malnutrition on total clearance $(\mathrm{CL})$ and half-life $\left(\mathrm{t}_{12}\right)$ of first-line anti-TB drugs primarily metabolised by the liver or primarily eliminated in the kidneys

\begin{tabular}{|c|c|c|c|c|c|c|c|c|}
\hline \multirow[b]{2}{*}{ Anti-TB drug } & \multirow[b]{2}{*}{$\begin{array}{l}\text { Severity of } \\
\text { malnutrition }\end{array}$} & \multicolumn{2}{|c|}{ Mean CL (mL/min/kg) } & \multirow[b]{2}{*}{$\begin{array}{l}\text { Comment on drug CL } \\
\text { (based on } p \text { values) }\end{array}$} & \multicolumn{2}{|c|}{ Mean $t_{1 / 2}$ (hour) } & \multirow[b]{2}{*}{$\begin{array}{l}\text { Comment on drug } t_{1 / 2} \\
\text { (based on } p \text { values) }\end{array}$} & \multirow[b]{2}{*}{ Reference } \\
\hline & & $\begin{array}{l}\text { Normal } \\
\text { healthy } \\
\text { controls }\end{array}$ & $\begin{array}{l}\text { Malnourished } \\
\text { children }\end{array}$ & & $\begin{array}{l}\text { Normal } \\
\text { healthy } \\
\text { controls }\end{array}$ & $\begin{array}{l}\text { Malnourished } \\
\text { children }\end{array}$ & & \\
\hline \multirow[t]{5}{*}{ Isoniazid } & Severe. & $125.7 \pm 0.0^{*}$ & $329.4 \pm 0.0^{*}$ & $\begin{array}{l}\text { Significantly increased in } \\
\text { malnutrition. }\end{array}$ & $1.03 \pm 0.0$ & $0.73 \pm 0.0$ & $\begin{array}{l}\text { Significantly decreased in } \\
\text { malnutrition. }\end{array}$ & 19 \\
\hline & Non-severe. & $4.1 \pm 0.5$ & $2.9 \pm 0.3$ & $\begin{array}{l}\text { Not significantly } \\
\text { decreased in } \\
\text { malnutrition. }\end{array}$ & $3.6 \pm 0.3$ & $3.90 \pm 0.3$ & $\begin{array}{l}\text { Not significantly } \\
\text { increased in malnutrition. }\end{array}$ & 9 \\
\hline & Non-severe. & - & - & Insufficient evidence. & $1.78 \pm 0.0$ & $1.82 \pm 0.0$ & $\begin{array}{l}\text { Not significantly } \\
\text { increased in malnutrition. }\end{array}$ & 20 \\
\hline & Severe and non-severe. & - & - & Parameter not assessed. & - & - & Parameter not assessed. & 11 \\
\hline & Severe and non-severe. & - & - & Parameter not assessed. & - & - & Parameter not assessed. & 21 \\
\hline \multirow[t]{2}{*}{ Rifampicin } & $\begin{array}{l}\text { Severe and non-severe } \\
\text { combined. }\end{array}$ & $8.2 \pm 0.0$ & $8.2 \pm 0.2$ & No significant change. & $2.7 \pm 0.1$ & $2.9 \pm 0.0$ & $\begin{array}{l}\text { Not significantly } \\
\text { increased in malnutrition. }\end{array}$ & 22 \\
\hline & Severe and non-severe. & - & - & Parameter not assessed. & - & - & Parameter not assessed. & 11 \\
\hline \multirow[t]{3}{*}{ Pyrazinamide } & Severe and non-severe. & - & - & Parameter not assessed. & - & - & Parameter not assessed. & 10 \\
\hline & Severe and non-severe. & - & - & Parameter not assessed. & - & - & Parameter not assessed. & 11 \\
\hline & Severe and non-severe. & - & - & Parameter not assessed. & - & - & Parameter not assessed. & 21 \\
\hline \multirow[t]{2}{*}{ Ethambutol } & Non-severe. & $33.6 \pm 14.2$ & $67.0 \pm 91.2$ & $\begin{array}{l}\text { Not significantly } \\
\text { increased in malnutrition. }\end{array}$ & $9.7 \pm 4.0$ & $7.4 \pm 5.6$ & $\begin{array}{l}\text { Not significantly } \\
\text { decreased in malnutrition. }\end{array}$ & 10 \\
\hline & Severe and non-severe. & - & - & Parameter not assessed. & - & - & Parameter not assessed. & 11 \\
\hline
\end{tabular}

*Value in $\mathrm{mL} / \mathrm{min}$.

TB, tuberculosis. 
hepatitis risks are increased with concomitant use of INH and RMP, carbamazepine or phenobarbital. $^{15}$ Other observational studies have indicated hepatotoxicity of RMP in children when used alone or used concurrently with INH. ${ }^{16}{ }^{17}$ In all these reports, the plasma levels of the anti-TB drugs were not determined among patients who had hepatotoxicity.

The WHO revised guidelines for the treatment of TB in children recommend increased INH, RMP and PZA dosages according to body weight. These recommendations were based on evidence from pharmacokinetic studies suggesting that young children require higher dosages of the drugs than adolescents and adults to achieve desired serum concentrations, and observational cohort studies reported that the higher dosages were rarely associated with increased risk of toxicity in children. ${ }^{18}$ This is rather a practical approach. However, many of the anti-TB toxicity studies are observational and not specific for malnourished children. It may therefore not be appropriate to generalise such safety data to children who are severely malnourished and/or HIV-infected children.

Until more data are available, routine monitoring by the clinicians of malnourished children receiving weight-based drug regimens is necessary. Clinical studies would be helpful to know the impact of reduced total drug clearance on the incidence of drug effectiveness and toxicity, morbidity and mortality in malnourished children with TB.

In summary:

- It may be safe to use doses lower than the WHO recommended doses of INH, RMP and PZA for acutely malnourished children with TB. However, doses should be increased gradually following nutritional recovery, according to the change in BMI, or weight-for-age and weightfor-height $\mathrm{z}$-scores.

- The current WHO guidelines for TB treatment should be modified for severely malnourished children and should clearly define dosing of anti-TB drugs for malnourished and well-nourished children.
- The existing algorithms for TB management in children should be revised to accommodate malnourished and well-nourished children with or without HIV infection. Scaling down the anti-TB doses during acute malnutrition and reverting to the WHO recommended doses according to the change in nutritional status of a child should form an integral part of the algorithms.

\section{Contributors Both authors contributed equally.}

Funding The authors have not declared a specific grant for this research from any funding agency in the public, commercial or not-for-profit sectors.

Competing interests None declared.

Patient consent Not required.

Provenance and peer review Commissioned; internally peer reviewed.

(C) Author(s) (or their employer(s)) 2018. No commercial re-use. See rights and permissions. Published by BMJ.

$$
\text { A) Check for updates }
$$

To cite: Oshikoya KA, Senbanjo IO. Arch Dis Child 2018;103:1101-1103.

Received 19 April 2018

Revised 2 August 2018

Accepted 7 August 2018

Published Online First 21 August 2018

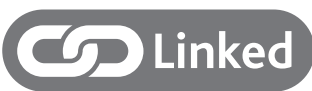

- http://dx.doi.org/10.1136/archdischild-2017313910

Arch Dis Child 2018;103:1101-1103.

doi:10.1136/archdischild-2018-314972

\section{REFERENCES}

1 Graham SM, Sismanidis C, Menzies HJ, et al. Importance of tuberculosis control to address child survival. Lancet 2014;383:1605-7.

2 World Health Organization. Global tuberculosis report, 2016. WHO/HTM/ TB/2016.13. Geneva, Switzerland: WHO, 2016. http://apps.who.int/iris/bitstream/10665/ 250441/1/9789241565394-eng.pdf?ua=1 (accessed Apr 2017).

3 World Health Organization. Tuberculosis. fact sheet, reviewed january 2018. http://www.who.int/ mediacentre/factsheets/fs104/en/

4 Karyadi E, Schultink W, Nelwan RH, et al. Poor micronutrient status of active pulmonary tuberculosis patients in Indonesia. J Nutr 2000;130:2953-8.

5 Lönnroth K, Castro KG, Chakaya JM, et al. Tuberculosis control and elimination 2010-50: cure, care, and socia development. Lancet 2010;375:1814-29.
6 Patel LN, Detjen AK. Integration of childhood TB into guidelines for the management of acute malnutrition in high burden countries. Public Health Action 2017:7:110-5.

7 Oshikoya KA, Senbanjo IO. Pathophysiological changes that affect drug disposition in protein-energy malnourished children. Nutr Metab 2009;6:50.

8 Oshikoya KA, Sammons HM, Choonara I. A systematic review of pharmacokinetics studies in children with protein-energy malnutrition. Eur J Clin Pharmacol 2010;66:1025-35.

9 Roy V, Gupta D, Gupta P, et al. Pharmacokinetics of isoniazid in moderately malnourished children with tuberculosis. Int J Tuberc Lung Dis 2010;14:374-6.

10 Graham SM, Bell DJ, Nyirongo S, et al. Low levels of pyrazinamide and ethambutol in children with tuberculosis and impact of age, nutritional status, and human immunodeficiency virus infection. Antimicrob Agents Chemother 2006;50:407-13.

11 Mukherjee A, Velpandian T, Singla M, et al. Pharmacokinetics of isoniazid, rifampicin, pyrazinamide and ethambutol in Indian children. BMC Infect Dis 2015; 15:126.

12 Science M, Ito S, Kitai I. Isoniazid toxicity in a 5-yearold boy. CMAJ 2013;185:894-6.

13 Chang SH, Nahid P, Eitzman SR. Hepatotoxicity in children receiving isoniazid therapy for latent tuberculosis infection. J Pediatric Infect Dis Soc 2014;3:221-7.

14 Centers for Disease Control and Prevention (CDC) Severe isoniazid-associated liver injuries among persons being treated for latent tuberculosis infection United States, 2004-2008. MMWR Morb Mortal Wkly Rep 2010;59:224-9.

15 The Global Alliance for TB Drug Development (TB Alliance). Isoniazid. Tuberculosis 2008;88:112-6.

16 Al-Dossary FS, Ong LT, Correa AG, et al. Treatment of childhood tuberculosis with a six month directly observed regimen of only two weeks of daily therapy. Pediatr Infect Dis J 2002;21:91-7.

17 Swaminathan S, Raghavan A, Duraipandian M, et al. Short-course chemotherapy for paediatric respiratory tuberculosis: 5-year report. Int J Tuberc Lung Dis 2005;9:693-6.

18 Graham SM, Grzemska M, Gie RP. The background and rationale for a new fixed-dose combination for firstline treatment of tuberculosis in children. Int J Tuberc Lung Dis 2015;19(Suppl 1):3-8.

19 Buchanan N, Eyberg C, Davis MD. Isoniazid pharmacokinetics in kwashiorkor. S Afr Med J 1979;56:299-300.

20 Seifart HI, Donald PR, de Villiers JN, et al. Isoniazid elimination kinetics in children with protein-energy malnutrition treated for tuberculous meningitis with a four-component antimicrobial regimen. Ann Trop Paediatr 1995; 15:249-54.

21 Dayal R, Singh Y, Agarwal D, et al. Pharmacokinetic study of isoniazid and pyrazinamide in children: impact of age and nutritional status. Arch Dis Child 2018;103:1150-4.

22 te Brake LH, Ruslami R, Later-Nijland $H$, et al. Exposure to total and protein-unbound rifampin is not affected by malnutrition in Indonesian tuberculosis patients. Antimicrob Agents Chemother 2015;59:3233-9. 